\title{
Tactile responses in pure-tone audiometry: a saccule function?
}

\author{
Thomas Braun · Julia Louza • Robert Gürkov • \\ Alexander Berghaus $\cdot$ Eike Krause
}

Received: 8 April 2013/Accepted: 19 April 2013/Published online: 25 April 2013

(C) Springer-Verlag Berlin Heidelberg 2013

Dear Editor,

As generally accepted, low-frequency bone-conduction thresholds obtained in the $35-55 \mathrm{~dB}$ range are often tactile responses and not due to auditory stimulation [4]. Since it is recently known that low-frequency air- and bone-conducted stimuli can be used to test otolithic function also in humans [2], we wondered if such "false-positive" boneconduction thresholds in pure-tone audiometry could be linked to saccular function evaluated by cervical vestibular evoked myogenic potentials, cVEMP [1]. We therefore correlated the presence or the absence of obvious "sensation thresholds" in 29 patient (58 ears) with bilateral functional deafness (listed for cochlear implantation) with the respective presence or absence of cVEMPs when applying $500 \mathrm{~Hz}$ tone bursts $(105 \mathrm{~dB}$ SPL, $7 \mathrm{~ms}$ duration, $5 / \mathrm{s}$ ) via headphones and recording ipsilateral sternocleidomastoid muscle activity with surface electrodes [3].

When summarized in a $2 \times 2$ crosstab, there was no evident statistical correlation $\left(\chi^{2}=0.0296, p>0.05\right)$.
Since strong correlations should be visible in such a number of cases, we conclude from our data that tactile responses in pure-tone audiometry are probably not connected to saccule function, but to other sensory structures.

Conflict of interest None.

\section{References}

1. Colebatch JG, Halmagyi GM, Skuse NF (1994) Myogenic potentials generated by a click-evoked vestibulocollic reflex. J Neurol Neurosurg Psychiatry 57:190-197

2. Curthoys IS, Vulovic V, Burgess AM et al (2011) The basis for using bone-conducted vibration or air-conducted sound to test otolithic function. Ann N Y Acad Sci 1233:231-241

3. Krause E, Wechtenbruch J, Rader T et al (2009) Influence of cochlear implantation on sacculus function. Otolaryngol Head Neck Surg 140:108-113

4. Roeser RJ, Valente M, Hosford-Dunn H (eds) (2007) Audiology. Diagnosis. Thieme, New York
T. Braun $(\bowtie) \cdot$ J. Louza $\cdot$ R. Gürkov · A. Berghaus · E. Krause Department of Otorhinolaryngology, Head and Neck Surgery, Ludwig Maximilian University, Marchioninistraße 15, 81377 Munich, Germany

e-mail: thomas.braun@med.uni-muenchen.de 